\section{Aircraft for Pleasure}

\section{By Bertram W. Williams}

IF the history of the automobile is to be 1 repeated, the airplane must first prove itself to be a reliable and efficient instrument of pleasure before it can hope to be a commercial success. The business man by the very nature of things must be cautions in experimenting with new and practically unproven methods. It has taken years to impress upon the public that the air is as safe a route of trave as any other provided proper machines and precautions are used, apart from it being infinitely more swift and comfortable. It now remains to convince commercial interests that the airplane is an economical means of transportation.

The success of aircraft in the war, far from advancing the cause of civilian aviation, has really made the average business man to be somewhat suspicious of its use as a substitute or even auxiliary of the proven automobile and truck. This idea has not been corrected by the daily press, which still persists in regarding all kinds of flying machines as dangerous and exnensive toys. To combat this theory it is essential that the public be educated to look upon flying as nothing out of the ordinary-neither a hazardous nor ver costly occupation. When that is accomplished, the vast field of its uses in the future will soon be realized.

In the past, manufacturers have given little attention to the general public as a possible customer; they have rather concentrated on Government and Wa Office orders, where excessive power has been the dominating need, and cost of construction and econom of upkeep neglible factors. Once the aircraft indus try devotes its time to making these two latter details their chief consideration, flying will soon become as their chief consideratid

The automobile was for a long time dependent on good roads before it became popular with the genera public, but if present-day machines were only capabl of traveling on paved highways, they would still be comparative rarety in this country, where four-fifth of the roads are far from ideal. Just so must the airplane be made more or less independent of large and specially prepared landing fields.

One of the chief exhibits at the San Francisco aircraft exposition, held some time ago, was a small machine built solely for pleasure purposes by the Longhead organization of Santa Barbara, and ther are so many novel and interesting features about thi miniature airplane that it is worth describing in detail The "S-1," as it is called, is a single-seater biplane with a wing span of 20 feet, and a total weight empty of only 400 pounds. Everything about this little air plane denotes a refinement and finish worthy of the best French and English machines, and lacking; it must be confessed, in most of our domestic craft. The fuselage is of the monocoque type, consisting of a thin shell of plywood reinforced by transverse bulkheads. Thi form of fuselage has long been acknowledged to be the most successful on account of its ideal streamline form, and its strength in proportion to its weight Heretofore, it has, however, been little used on account of the laborious methods necessary which made it exceedingly expensive. The shell in the Longhead model

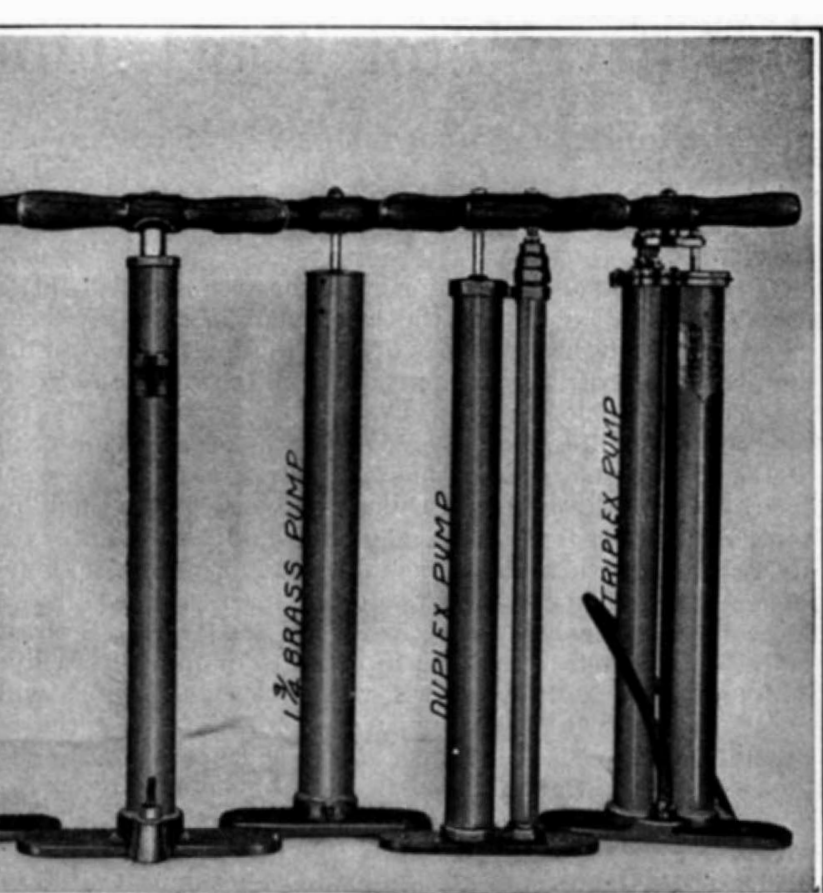

The Efficient Tire Pump By Ralph Howard

SINCE the time when pneumatic tires proved their superiority over hard and cushion construction for bicycle equipment, the pump has been a tool for serious consideration. Forgotten and often abused in long periods of idleness, to be hauled out in times of stress and hurry, it has never enjoyed much popularity.

it has never enjoyed much popularity.
Idleness often destroys its usefulness

more than operation. Satisfactory performance depends on flexibility of the leather cups. This is retained by oil. Tubes are often dented or leaks caused by carelessness. If the love of the fisherman for his rod or the hunter for his favorite gun could be felt by the motorist for his tire pump, much of the difficulty would be overcome.

The great increase in volume of the automobile tire complicated the problem. Single action pumps of small diameters had been used. Makers at once turned to larger diameters, but found this plan had its limits, as it was humanly impossible to push down the large plunger against the higher back pressure. It was found that a 11/4-inch cylinder was about as large as could be used to get the specified pressures. The pumps already being check valve type and ending with the triplex type

is produced by applying three complete layers of plywood to a mold the shape of the body; binding cloth and casein glue being applied between the layers, which are then subjected to a uniform air pressure of 20 are then subjected to a uniform air pressure of 20
pounds to the square inch, which is maintained over pounds to the square inch, which is maintained over the entire surface until the glue has set. This process produces a wooden shell one-eighth of an inch thick which is said to be stronger for its weight than any other fuselage yet developed. The upper and lower wings are supported by a V-shaped strut near the wing tips which is solidly bolted to the upper wing spars and fastened to the lower wing by a simple but rigid pin connection. The most novel and original features of this machine are the air brake and the position of the radiator. In the former, the lower wing spar is made to pivot at the body, allowing the whole wing to rotate, not only forming a very efficient lateral control, but allowing the lower plane to be thrown into a vertical position which provides an extremely effective brake, making it possible to stop the plane within about 70 feet of the point where the wheels first touch the ground, thus solving one of the chief problems of aircraft construction since the first flight of a heavier aircraft construction since the first fight of a heavier-
than-air machine. This simple and ingenious brake is operated by a separate lever beside the pilot's seat.

The designers claim that the machine will land at the exceedingly low speed of 25 miles per hour, while its maximum speed is said to be 75 miles per houra greater range than any other present-day type. There is no reason to doubt these figures, as the almost ideal shape of the fuselage and the general distribution of weight have made it possible to operate the machine weight have made it possible to operate the machine
with an engine of only 25 horse-power. In these days of gigantic horse-power one would be apt to scoff at such a puny power plant till it is remembered that Blerio crossed the English Channel in a far clumsier and heavier machine with an engine of similar power and decidedly inferior cooling qualities.

(Continued on page 35 ) longer than the average user would utilize in making a stroke, the capacity was thus fixed. To overcome this the two-cylinder pump was developed.

Since the energy necessary to push down a plunger against a given pressure varies directly in proportion with the area of the plunger, the idea was conceived

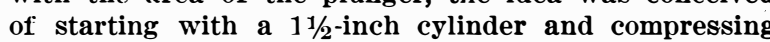
the air on the down stroke through a cross-over in the liase into a $7 / 8$-inch tube parallel to it. The $7 / 8$-inch cup acted as a check until the up stroke when it forced the charge into the tire combating the back pressure with its limited area. It was found that this pump could handle more than twice the amount of air per stroke of the single-action $11 / 4$-inch, while it met with less resistance in getting it through the tire nipple.

One pump maker has recently realized the advantage of carrying the compounding principle even one stage further, and has designed the triple pump. This takes the air into the top of a $13 / 4$-inch tube, delivers it on the down stroke into a 11/4-inch cylinder in exactly the same way as the double compound pump did. On the up stroke this air passes over at the top and is trapped in a $3 / 4$-inch tube from which it is expelled into the tire by that very small plunger.

The advantages gained were that the three-stage pump had five times the capacity per strole of a 11/4inch single and about twice that of the double. It combated back pressure on the down stroke when the weight of the body could be utilized. And yet the maximum operating effort was found by actual test to be almost equal. The greatest gain of all perhaps, was in retting air through the tire valve, as the flow of air became almost continuous, while with the other pumps, the singles especially, air was expelled in short, jerky gusts which permitted the tire valve to close after each stroke, and, of course, necessitated its reopening, thus greatly increasing the friction and the total amount of energy necessary to getting the tire up to pressure in a given time.

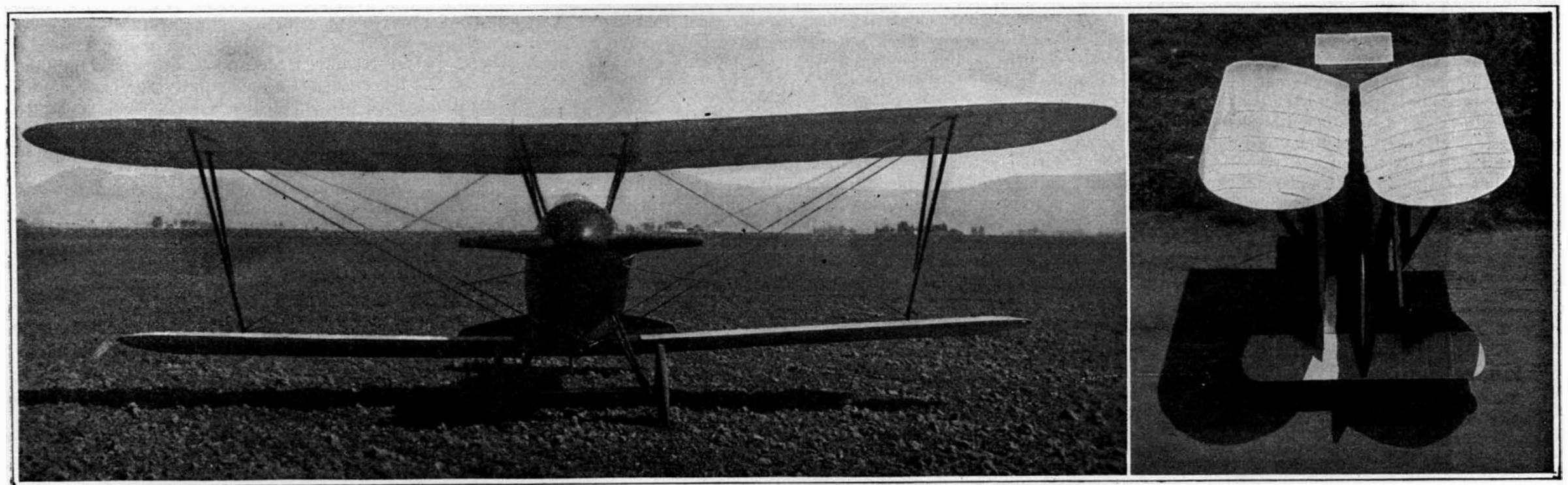

Two views of the Longhead biplane, which represents a serious American effort toward producing an airplane for general sport purposes 